\title{
$\gamma$-Radiation-Induced Solution Polymerization of Some Methyl Aryloxymethacrylates
}

\author{
Ramaswamy Devarajan, ${ }^{*}$ ThaikKannu Balakrishnan, ${ }^{* *}$ and M. SantaPPa \\ Department of Physical Chemistry, University of Madras, \\ A. C. College Campus, Madras-600 025, India. \\ Balasubramanian VISWANATHAN \\ Department of Chemistry, Indian Institute of Technology, \\ Madras-600 036, India.
}

(Received February 20, 1980)

\begin{abstract}
The kinetics of $\gamma$-radiation-induced solution polymerization of methyl phenoxymethacrylate (MPMA) and methyl p-cresoxymethacrylate (MCMA) in toluene has been studied at 30 and $0 \mathrm{C}$ and at dose rates of $0.3,0.15$, and $0.75 \mathrm{Mradh}^{-1}$.*** The rates of polymerization, which were found to increase with increasing monomer concentration, have direct dependence on dose rate and [monomer] and have inverse dependence on [solvent]. The apparent energies of activation measured at $0.3 \mathrm{Mrad} \mathrm{h}^{-1}$ for MPMA and MCMA respectively are: $46.8 \mathrm{~kJ}$ $\mathrm{mol}^{-1}$ and $11.7 \mathrm{~kJ} \mathrm{~mol}^{-1}$. The polymerization proceeded in spite of the presence of the inhibitor $p$ hydroxyphenyl methyl ether (PHME). This suggests that the mechanism of polymerization may be predominantly ionic. A suitable reaction scheme has been proposed.

KEY WORDS $\gamma$ Radiation / Solution Polymerization / Methyl Phenoxymethacrylate / Methyl p-Cresoxymethacrylate / Dose Rates / Kinetics / Reaction Scheme /
\end{abstract}

The kinetic behavior of $\gamma$-radiation-induced polymerization of methyl acrylate at a does rate of $30 \mathrm{rad} \mathrm{s}^{-1}$ was studied ${ }^{1,2}$ in the solvents toluene, ethyl chloride, tetrahydrofuran (THF) and triethylamine, at various temperatures $(-116$ to $25^{\circ} \mathrm{C}$ ) and in presence of the additives such as diphenylpicrylhydrazyl (DPPH) and benzoquinone. The authors observed that the rate of polymerization and molecular weight of the polymer increased with increasing monomer concentration and decreased with decreasing temperature. The dose-rate exponent varied from 0.5 to 1.0 with respect to the rate of polymerization and the system in all cases had low activation energies. We suggest

\footnotetext{
* Present address: NGM College, Pollachi-642001, India.

** Present address: Oklahoma State University, Stillwaters, Oklahoma 74078, USA.

*** In SI Units, $1 \mathrm{rad}=10^{-2} \mathrm{~Gy}$.
}

significant chain transfer to the solvent especially to triethylamine and coexistence, under these conditions, of free-radical and ionic routes in the polymerization process. Chapiro et al. ${ }^{3-5}$ observed a steady increase in the rate of polymerization with increasing monomer concentration and with the capacity of solvent to dissociate the multimolecular aggregates of methacrylic acid. In this radiochemical polymerization study in various solvents, they have also noticed a gradual decrease in the rate for toluene and hexane solutions. The suggestion that the additive biphenyl facilitates chain transfer, which decreases the molecular weight of poly(methyl methacrylate), was made ${ }^{6}$ in the study of polymerization of methyl methacrylate in pyridine and acetone solutions containing naphthalene, biphenyl, and benzene. Radiation-induced polymerization of styrene has been investigated by Ueno et al. ${ }^{7}$ under extremely dry conditions and has been shown to proceed predominantly through 
ionic intermediates, both for styrene in bulk and in solvents such as dichloromethane at various temperatures. Evidence for a cationic mechanism has been obtained from the effect of additives and from the magnitude of copolymerization reactivity ratio with monomers such as $\alpha$-methylstyrene, isobutyl vinyl ether. ${ }^{8}$ The rate of polymerization varied with the dose rate and with the exponent $\left(R_{\mathrm{p}} \alpha I^{n}\right) n$ varying from unity to 0.6 . A mechanism involving bimolecular termination of free ions has been deduced. In addition, strong retardation by scavengers of high proton affinity substances like water, diethyl ether, ammonia provide evidence that the propagation step mainly involves free cations. ${ }^{8}$ The coexistence of radical and ionic mechanisms at $-40^{\circ} \mathrm{C}$ with a predominance of ionic routes at lower temperatures, the direct dependence of dose rate on $R_{\mathrm{p}}$ and a strong retardation in the rate of polymerization by the addition of diethylamine were observed $^{9}$ in the $\gamma$-ray-induced polymerization of para-halosubstituted styrenes in $\mathrm{CH}_{2} \mathrm{Cl}_{2}$. Murata ${ }^{10}$ carried out the polymerization of $N$-vinylphthalimide in $N, N$-dimethylformamide and showed that the dose-rate exponent with respect to $R_{\mathrm{p}}$ was 0.8 and predicted a bimolecular termination mechanism.

Recently two of the authors of this paper have reported $^{11}$ the syntheses of some methyl aryloxymethacrylates. The objectives of the present investigation are: (i) to determine the kinetic behaviour of $\gamma$-ray-induced solution polymerization of methyl phenoxymethacrylate (MPMA) and methyl $p$-methylphenoxymethacrylate (MCMA) in toluene at temperatures 0 and $30^{\circ} \mathrm{C}$ and at dose rates of $0.075,0.15$, and $0.3 \mathrm{Mrad} \mathrm{h}^{-1}$ and from the knowledge of the rates of polymerization of these monomers calculated for different concentrations and dose rates to make a comparative study between MPMA and MCMA in relation to their structures.

\section{EXPERIMENTAL}

The monomers MPMA and MCMA were freshly prepared before use. The sample of $p$-hydroxyphenyl methyl ether (PHME) from Koch-Light Laboratories, England, was used directly. Toluene, $\mathrm{AR} \mathrm{BDH}$ (India) was washed several times with concd $\mathrm{H}_{2} \mathrm{SO}_{4}$, water and $\mathrm{NaOH}$ and water, distilled and stored over sodium wire. For the purpose of polymerization, this sample was refluxed over dry bits of sodium for $12 \mathrm{~h}$ and distilled. This was stored over sodium and used as such.

The course of polymerization was followed using special dilatometers of Corning glass of wall thickness $5=\mathrm{mm}$ so as to minimize wall effects. The readings at various intervals of time were recorded by a sensitive $(0.001 \mathrm{~cm})$ cathetometer. For uniformity, each dilatometer had only two exposures and for the sake of reproducibility, the dilatometers were placed exactly at the same geometrically reproducible positions. Because of its free miscibility with the monomers and its low $G$ value $(0.14),{ }^{12}$ a factor to be considered for minimum participation of a solvent in the mechanism of polymerization toluene was chosen as the solvent. Dry nitrogen was passed for fifteen minutes into the monomer solutions, including those containing the inhibitor. The solutions were introduced immediately into the dilatometers, by means of a hypodermic syringe. ${ }^{15}$ As the dose rates employed were high, the concentrations of the monomers considered were also high.

The $\gamma$-source by BARC, India (Gamma chamber 900 ) with a maximum capacity of 2000 curies had a dose rate of $0.3 \mathrm{Mrad} \mathrm{h}^{-1}$ when these investigations were undertaken.

The dose rates were determined by Fricke dosimetry, using $G\left(\mathrm{Fe}^{+++}\right)$value of 15.5. These values were utilized for calculating dose rates absorbed by the monomers at various concentrations.

The ${ }^{1} \mathrm{H}-\mathrm{NMR}$ spectra, for poly(methyl phenoxymethacrylate) PMPMA and poly(methyl $p$ methylphenoxymethacrylate) PMCMA obtained by the $\gamma$ irradiation at $0.3 \mathrm{Mrad} \mathrm{h}^{-1}$ on the solutions of MPMA and MCMA in toluene. were recorded at $35^{\circ} \mathrm{C}$ in a $90 \mathrm{MHz}$ Perkin-Elmer R-32 spectrometer using ten percent of the polymers in trifluoroacetic acid (TFA).

\section{RESULTS AND DISCUSSION}

\section{Influence of Monomer Concentration}

The title polymerization of MPMA and MCMA in toluene at various monomer concentrations was carried out at 0 and $30^{\circ} \mathrm{C}$ and at the dose rates of $0.3,0.15$, and $0.075 \mathrm{Mrad} \mathrm{h}^{-1}$. The conversion of the monomers in $\mathrm{moll}^{-1}$ per given intervals of time were plotted against each other. It can be seen from the values given in Tables I and II that, as reported for many systems, ${ }^{1-5,17}$ in both MPMA and 
Gamma-Radiation-Induced Solution Polymerization

Table I. $R_{\mathrm{p}}$ values of MPMA obtained under various conditions

\begin{tabular}{|c|c|c|c|c|c|}
\hline \multirow{2}{*}{$\frac{\text { Temp }}{{ }^{\circ} \mathrm{C}}$} & \multirow{2}{*}{$\begin{array}{l}\text { Whether } \\
\text { PHME } \\
\text { present }\end{array}$} & \multirow{2}{*}{$\frac{\text { Concn }}{\mathrm{mol} \mathrm{l}^{-1}}$} & \multicolumn{3}{|c|}{$R_{\mathrm{p}} / \mathrm{mol} \mathrm{l}^{-1} \mathrm{~s}^{-1}$} \\
\hline & & & at $0.3 \mathrm{Mrad} \mathrm{h}^{-1}$ & at $0.15 \mathrm{Mrad} \mathrm{h}^{-1}$ & at $0.075 \mathrm{Mrad} \mathrm{h}^{-1}$ \\
\hline 30 & - & 163.35 & $1.54 \times 10^{-2}$ & $8.13 \times 10^{-3}$ & $6.94 \times 10^{-3}$ \\
\hline 30 & - & 35.43 & $4.17 \times 10^{-3}$ & $1.75 \times 10^{-3}$ & $1.39 \times 10^{-3}$ \\
\hline 30 & - & 11.27 & $2.78 \times 10^{-3}$ & $3.54 \times 10^{-3}$ & $5.56 \times 10^{-4}$ \\
\hline 30 & Present & 11.27 & $1.50 \times 10^{-4}$ & - & $2.79 \times 10^{-5}$ \\
\hline 0 & - & 11.27 & $3.58 \times 10^{-4}$ & - & - \\
\hline 30 & - & 4.97 & $6.25 \times 10^{-4}$ & $1.75 \times 10^{-4}$ & $2.02 \times 10^{-4}$ \\
\hline 30 & - & 2.8 & $8.33 \times 10^{-5}$ & $1.16 \times 10^{-4}$ & $7.78 \times 10^{-4}$ \\
\hline
\end{tabular}

Table II. $R_{\mathrm{p}}$ values of MCMA obtained under various conditions

\begin{tabular}{|c|c|c|c|c|c|}
\hline \multirow{2}{*}{$\frac{\text { Temp }}{{ }^{\circ} \mathrm{C}}$} & \multirow{2}{*}{$\begin{array}{l}\text { Whether } \\
\text { PHME } \\
\text { present }\end{array}$} & \multirow{2}{*}{$\frac{\text { Concn }}{\operatorname{mol~1^{-1}}}$} & \multicolumn{3}{|c|}{$R_{\mathrm{p}} / \mathrm{mol} \mathrm{1}^{-1} \mathrm{~s}^{-1}$} \\
\hline & & & at $0.3 \mathrm{Mrad} \mathrm{h}^{-1}$ & at $0.15 \mathrm{Mrad} \mathrm{h}^{-1}$ & at $0.075 \mathrm{Mrad} \mathrm{h}^{-1}$ \\
\hline 30 & - & 154.76 & $2.51 \times 10^{-2}$ & $1.58 \times 10^{-2}$ & $3.79 \times 10^{-3}$ \\
\hline 30 & - & 34.60 & $5.33 \times 10^{-3}$ & $2.30 \times 10^{-3}$ & $7.29 \times 10^{-4}$ \\
\hline 30 & - & 10.67 & $1.76 \times 10^{-3}$ & $6.25 \times 10^{-4}$ & $2.00 \times 10^{-4}$ \\
\hline 30 & Present & 10.67 & $6.24 \times 10^{-4}$ & - & $1.88 \times 10^{-4}$ \\
\hline 0 & - & 10.67 & $1.00 \times 10^{-3}$ & - & - \\
\hline 30 & - & 4.71 & $8.44 \times 10^{-4}$ & $3.30 \times 10^{-4}$ & $9.17 \times 10^{-5}$ \\
\hline 30 & - & 2.67 & $4.16 \times 10^{-4}$ & $2.00 \times 10^{-4}$ & $6.04 \times 10^{-5}$ \\
\hline
\end{tabular}

MCMA at all dose rates under consideration, the rates of polymerization, $R_{\mathrm{p}}$, increased steadily with increase in monomer concentrations, $[\mathrm{M}]$ and decreased with decrease in temperature. From the $R_{\mathrm{p}}$ values thus obtained at $30^{\circ} \mathrm{C}$ for various [M], plots of $\log R_{\mathrm{p}}$ vs. $\log [\mathrm{M}]$ were made. These plots are given in Figures 1 and 2 for MPMA and MCMA respectively. It is evident that $R_{\mathrm{p}}$ is in direct proportion to $[\mathrm{M}]$ for both monomers.

In the cationic polymerization at $-78^{\circ} \mathrm{C}$ of $\mathrm{HCHO}$, in toluene at the dose rates of $1.78 \times 10^{3}$ $\mathrm{radh}^{-114}$ and $1.3 \times 10^{3} \mathrm{radh}^{-115}$ and in methylene chloride at the dose rate of $4.39 \times 10^{3} \mathrm{rad} \mathrm{h}^{-1},{ }^{14}$ the order with respect to $\mathrm{HCHO}$ was shown to be two, whereas in ether at a dose rate of $1.33 \times 10^{3} \mathrm{radh}^{-114}$ the order was established as one. The kinetics and mechanism of cationic polymerization of cyclopentadiene induced at $-78^{\circ} \mathrm{C}$ by ${ }^{60} \mathrm{Co}$ at a dose rate of $10^{4}-10^{5} \mathrm{rad} \mathrm{h}^{-1}$ in presence of $\mathrm{CH}_{2} \mathrm{Cl}_{2}$ were studied by Miura and Maruko ${ }^{16}$ and the order with respect to monomer was determined as two. These observations indicate that

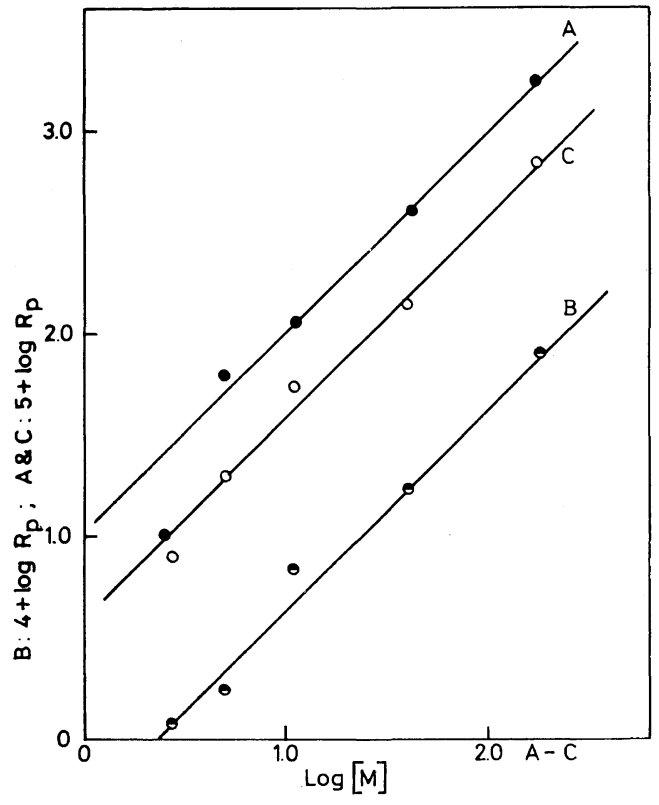

Figure 1. Plot of $\log R_{\mathrm{p}} v s . \log [\mathrm{M}]$ for MPMA: A, 0.3 $\operatorname{Mrad~h}^{-1}$; B, 0.15 $\mathrm{Mrad} \mathrm{h}^{-1} ; \mathrm{C}, 0.075 \mathrm{Mrad} \mathrm{h}^{-1}$. 


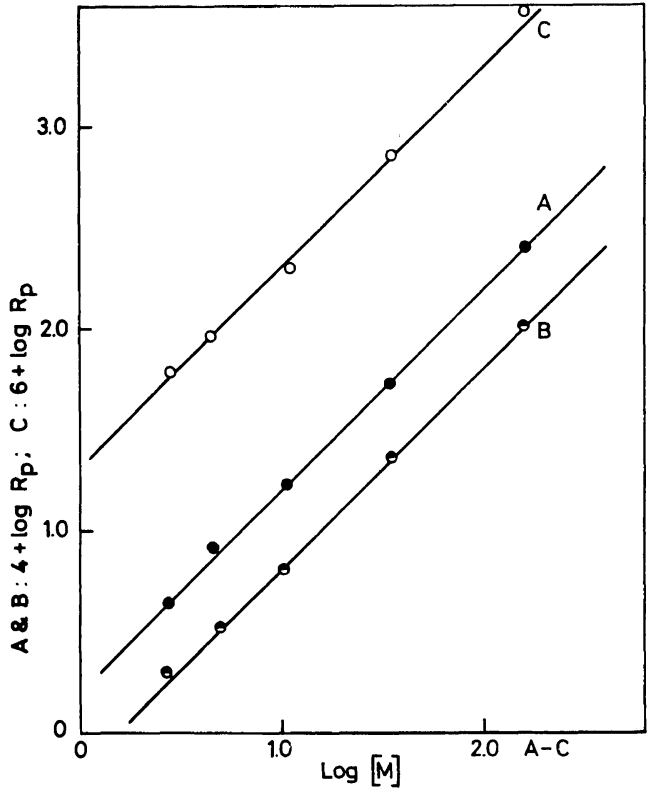

Figure 2. Plot of $\log R_{\mathrm{p}} v s . \log [\mathrm{M}]$ for MCMA: A, 0.3 Mrad hi-1; B, 0.15 $\mathrm{Mrad} \mathrm{h}^{-1} ; \mathrm{C}, 0.075 \mathrm{Mrad} \mathrm{h}^{-1}$.

the solvent seems to decide the order of the monomer in solution polymerization. However, as is evident from these observations, the nature of the monomer could also decide the order in the polymerization. Sakurada et al. ${ }^{17}$ polymerized styrene in dichloromethane at $-78^{\circ} \mathrm{C}$ and at a dose rate of $10^{4}$ $\mathrm{rad} \mathrm{h}^{-1}$ and showed that the rate of polymerization increased linearly with monomer concentration. Polymerization of ethylene in various solvents at room temperature ${ }^{18}$ and at a dose rate of $2.5 \times 10^{4}$ $\mathrm{rad} \mathrm{h}^{-1}$ and also at high pressures at a dose rate of $8.5 \times 10^{5} \mathrm{rad} \mathrm{h}^{-119}$ has been shown to proceed by a free-radical mechanism. In the $\gamma$-ray-induced polymerization of nitroethylene in THF at $-78^{\circ} \mathrm{C}$, the $R_{\mathrm{p}}$ was linearly related to the dose rate and the monomer. ${ }^{20}$ The mechanism in this case was shown to be anionic.

Therefore, besides pressure, temperature, and dose rate, solute and solvent also affect the kinetics and mechanism of polymerization. ${ }^{6}$

\section{Influence of Solvent}

The $\log R_{\mathrm{p}}$ values of MPMA and MCMA for various concentrations and dose rates under consideration were plotted against the logarithmic values for the corresponding solvent concentrations

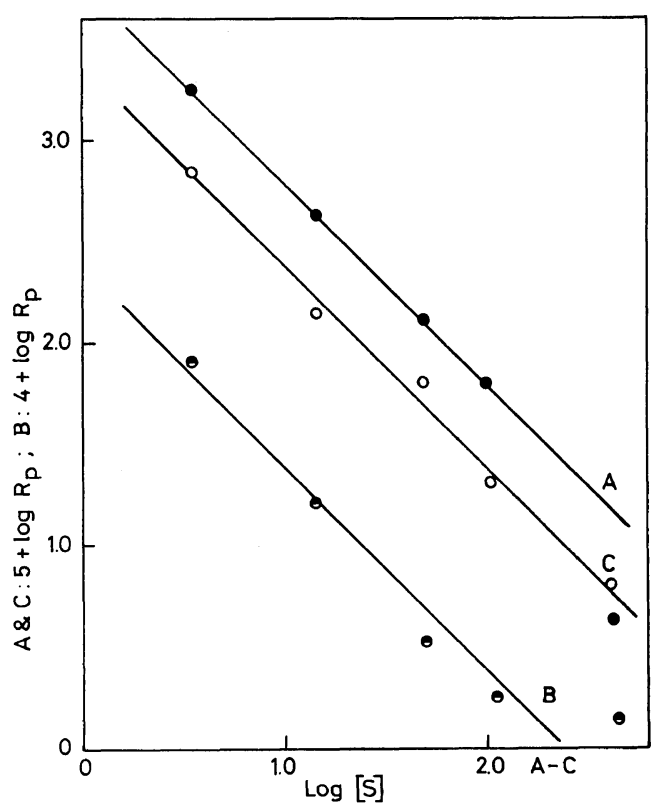

Figure 3. Plot of $\log R_{\mathrm{p}} v s . \log$ [S] for MPMA: A, 0.3 $\operatorname{Mrad~h}^{-1} ; \mathrm{B}, 0.15 \mathrm{Mrad} \mathrm{h}^{-1} ; \mathrm{C}, 0.075 \mathrm{Mrad} \mathrm{h}^{-1}$.

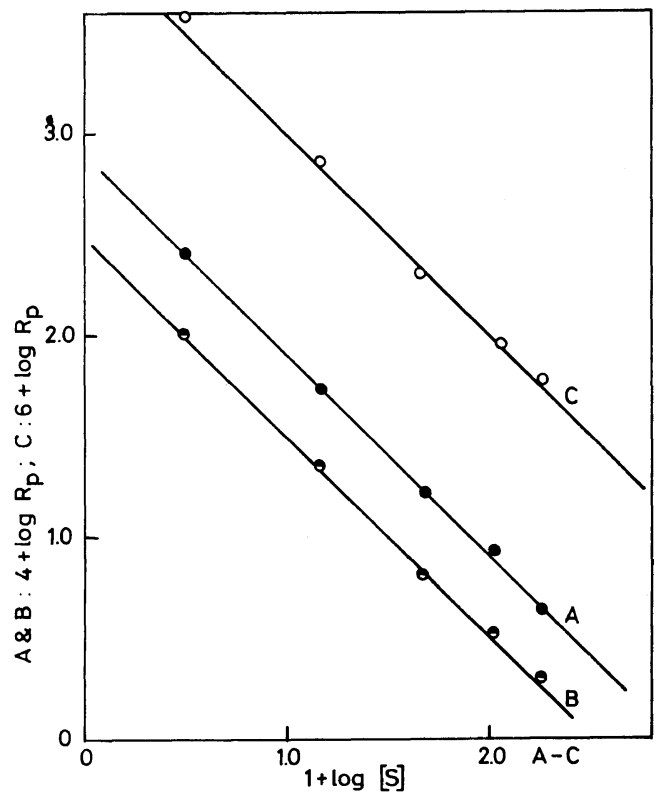

Figure 4. Plot of $\log R_{\mathrm{p}}$ vs. $\log$ [S] for MCMA: A, 0.3 $\operatorname{Mrad~h}^{-1} ; \mathrm{B}, 0.15 \mathrm{Mrad} \mathrm{h}^{-1} ; \mathrm{C}, 0.075 \mathrm{Mrad} \mathrm{h}^{-1}$.

$(\log [\mathrm{S}])$. These plots are given in Figures 3 and 4. A negative slope of value one in each case indicates that, in the process of polymerization, the order 
with respect to toluene is one.

Since all types of species (monomer, radicals, ions, and radical ions) may exist as solvated species, there is an effective competition for termination process between the species and solvent. The species produced during the radiolysis of toluene should be small and thus can diffuse relatively easily through the viscous medium and terminate the growing chain. It is assumed that, since such species is resonance stabilized they are incapable of initiation. The absence of any signal for the methyl protons in the ${ }^{1}$ HNMR spectrum of PMPMA would indicate a minimum participation of toluene in the process of polymerization.

\section{Influence of Dose Rate}

For both the monomers, the plots of the values of $R_{\mathrm{p}} v s$. the values of the dose rate absorbed (I), for a given concentration are linear (Figures 5 and 6) and also pass through the origin. The direct dependence of $R_{\mathrm{p}}$ on absorbed dose rate is therefore indicated. Notwithstanding the adequate purity of solutes and solvent and the absence of air, oxygen or moisture in the process, the large departure from the square root relationship of dose rate on $R_{\mathrm{p}}$ in the present system may indicate the contribution by ionic route

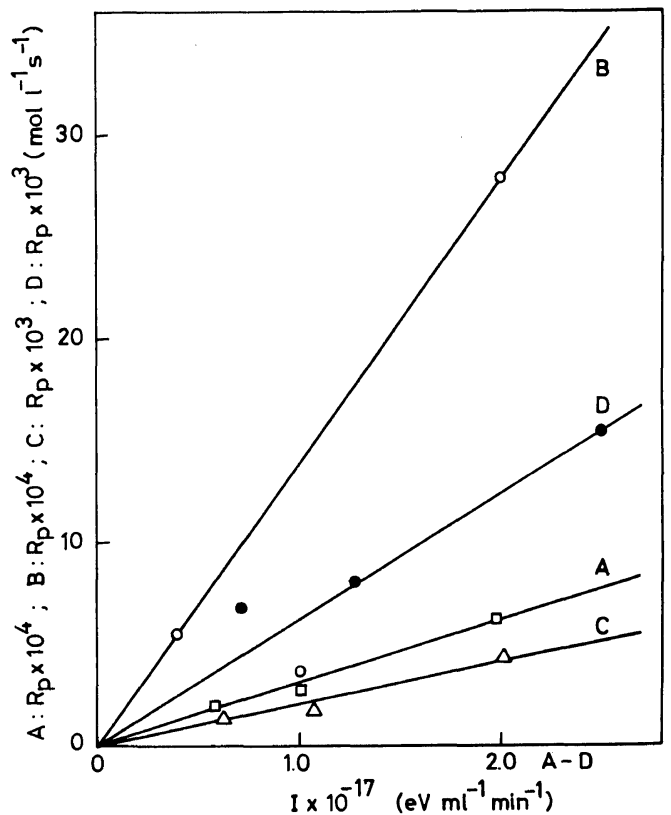

Figure 5. Plot of $R_{\mathrm{p}} v s$. dose rate for MPMA: A, 4.97 mol 1-1; B, $11.27 \mathrm{~mol} \mathrm{l}^{-1}$; C, $35.4 \mathrm{~mol} \mathrm{l}^{-1}$; C, $163.4 \mathrm{~mol}$ $1^{-1}$.

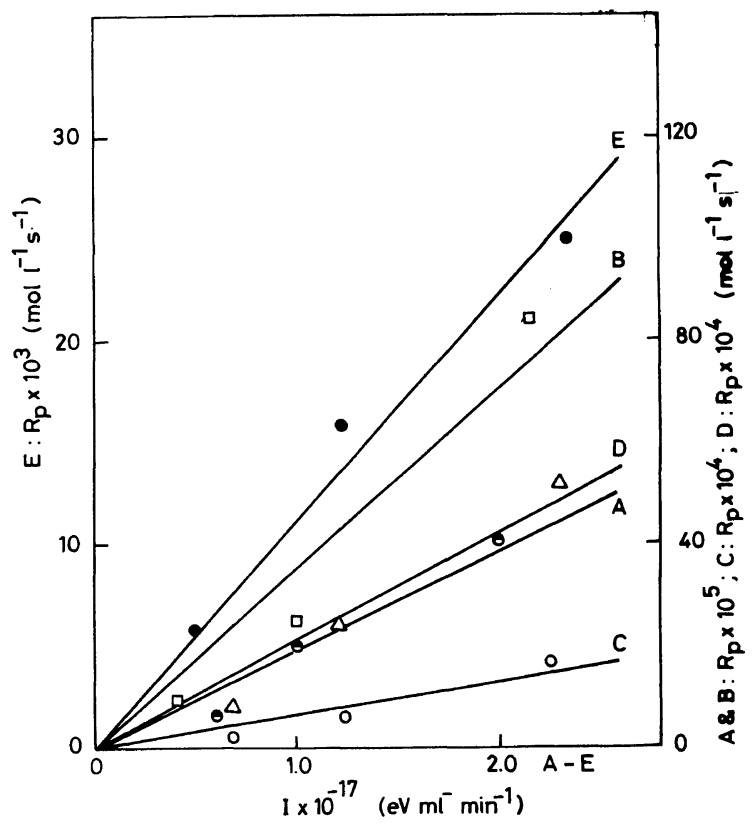

Figure 6. Plot of $R_{\mathrm{p}}$ vs. dose rate for MCMA: A, $2.67 \mathrm{moll}^{-1} ; \mathrm{B}, 4.71 \mathrm{moll}^{-1} ; \mathrm{C}, 10.67 \mathrm{~mol}^{-1}$; D, 34.6 moll-1; E, $154.8 \mathrm{moll}^{-1}$. 
also in th polymerization mechanism which seems to be complex.

The initial rates of polymerization at $0^{\circ} \mathrm{C}$ and at a dose rate of $0.3 \mathrm{Mradh}^{-1}$ were determined for MPMA at $11.27 \mathrm{moll}^{-1}$ and for MCMA at $10.67 \mathrm{moll}^{-1}$. These values along with the values for the same concentrations and dose rate at $30^{\prime \prime} \mathrm{C}$ (Tables I and II) were utilized in the Arrhenius equation for calculating the overall apparent energy of activation. These values are: MPMA, 46.9 $\mathrm{kJ} \mathrm{mol}^{-1}$ and MCMA, $11.7 \mathrm{~kJ} \mathrm{~mol}^{-1}$.

\section{Influence of Added Inhibitor}

Three percent solutions of the inhibitor PHME, with $10.67 \mathrm{moll}^{-1}$ and $11.27 \mathrm{moll}^{-1}$ toluene solutions of MCMA and MPMA respectively were prepared and the polymerization was carried out at $30^{\circ} \mathrm{C}$ and at dose rates of 0.3 and $0.075 \mathrm{Mradh}^{-1}$. The gram moles of monomer converted in the presence of the inhibitor were plotted against time (Figure 7). It is seen from the values given in Tables I and II that there is considerable reduction in the rates of polymerization in both systems; however, the process of polymerization still proceeded in spite of the presence of the inhibitor. Polymerization no longer takes place, if free-radical route alone is in operation since the additive PHME being a strong free-radical scavenger, completely suppresses this process. The retardation in rate means only partial suppression by PHME, i.e., the entire removal of the free-radical component from a complex system in which the free-radical and ionic components coexisted. An interesting possibility at this point is the involvement in the initiation and termination steps of the resonance stabilized phenolate ion which may be produced during the radiolysis of PHME itself. If this ion is presumed to terminate the polymerization process, then the inhibitor has a dual role of removing the free-radical component entirely and the ionic component partially. A similar observation has also been made in the case of DPPH. ${ }^{8}$ Therefore, the residual rate observed in presence of inhibitor may be attributed to the ionic component in a process where the free-radical and ionic mechanisms are in simultaneous operation.

The addition of DPPH as a radical inhibitor in the polymerization of $\mathrm{HCHO}^{21}$ and cyclopentadiene ${ }^{16}$ in $\mathrm{CH}_{2} \mathrm{Cl}_{2}$ lowers the conversion to about $50 \%$. The authors thus concluded that the mechanism is predominatly cationic.

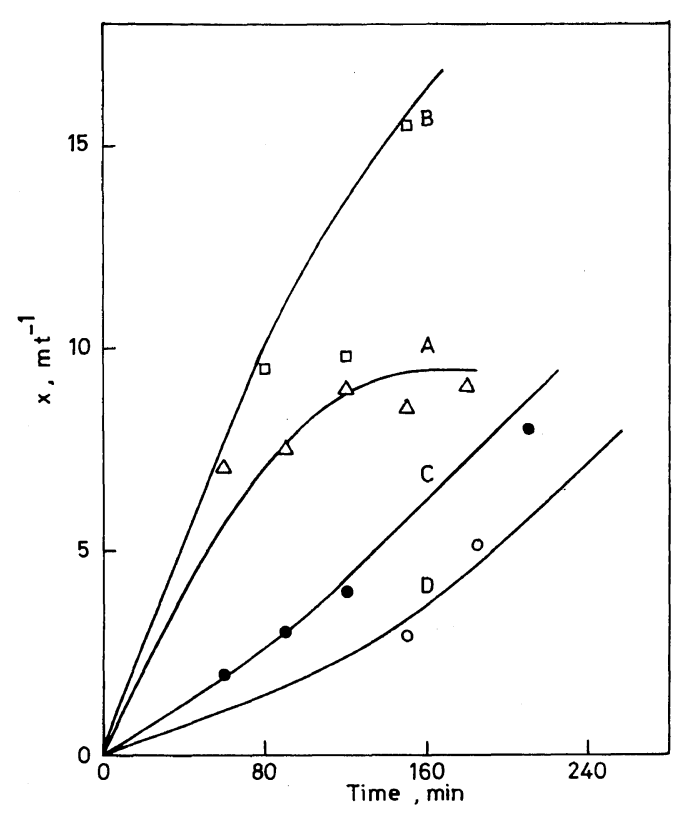

Figure 7. Plot of conversion vs. time in presence of inhibitor: A, MPMA $0.3 \mathrm{Mrad} \mathrm{h}^{-1}$; B, MPMA 0.075 $\mathrm{Mrad} \mathrm{h}^{-1}$; C, MCMA 0.3 $\mathrm{Mrad} \mathrm{h}^{-1}$; D, MCMA 0.075 Mrad h $^{-1}$

From the data available on the $\gamma$-radiationinduced polymerization of vinyl monomers, it is clear that free-radical, carbonium ions, and carbanions can all propagate simultaneously. Although suitable kinetic schemes have been formulated on the basis of the predominance of each of these species, ${ }^{21-23}$ which in turn is decided by the purity of the monomer, ${ }^{24-28}$ temperature, ${ }^{12}$ dose rate, ${ }^{24-28}$ or all associated glasswares, ${ }^{22}$ no comprehensive scheme is available to describe the polymerization behaviour over a wide range of experimental conditions. Thus the common features associated with ionic polymerization seem to be (i) the purity of the monomer (ii) high dose rate (iii) linear dependence of $R_{\mathrm{p}}$ on dose rate and (iv) the lowactivitation energy. ${ }^{29}$

Taking the above factors into account, in the $\gamma$-radiation-induced solution polymerization of MPMA and MCMA in toluene the dose rate employed, the direct dependence of $R_{\mathrm{p}}$ on dose rate $^{9,15}$ and the residual rates of polymerization even in the presence of PHME, all seem to favour a mechanism which has a preponderance of the ionic component. 


\section{Reaction Scheme}

The following scheme based on the one originally derived by Williams et $a l^{30}$ has been proposed to account for all the above-mentioned observations.

The scheme given below has been proposed on the assumption that the solvent $S$ does not participate in the initiation step,

$$
\begin{array}{cc}
\text { Monomer } & \mathrm{W} \longrightarrow \mathrm{M}_{\mathrm{i}}^{+}+\mathrm{M}_{\mathrm{i}}^{-} \\
R_{\mathrm{i}}=\frac{I G_{\mathrm{i}}}{100} &
\end{array}
$$

where $I$ is the exposure dose rate and $G_{\mathrm{i}}$ is the ionic consumption of the monomer.

Propagation and transfer,

$$
\begin{aligned}
& \mathrm{M}_{m}^{+}+\mathrm{M} \stackrel{k_{\mathrm{p}}}{\longrightarrow} \mathrm{M}_{m+1}^{+} \\
& \mathrm{M}_{m}{ }^{+}+\mathrm{S} \stackrel{k_{\mathrm{trs}}}{\longrightarrow} \mathrm{P}+\mathrm{S}^{+}
\end{aligned}
$$

Termination,

$$
\mathrm{M}_{m}{ }^{+}+\mathrm{M}_{n}{ }^{-} \stackrel{k_{\mathrm{t}}}{\longrightarrow} \mathrm{P}
$$

Then the stationary-state equations for chain termination and charge neutralization in presence of $S$ are,

$$
R_{\mathrm{i}}=k_{\mathrm{t}} \sum_{m}\left[\mathrm{M}_{m}^{+}\right]\left[\mathrm{M}_{n}^{-}\right]+k_{\mathrm{trs}}\left[\mathrm{S}^{+}\right]\left[\mathrm{M}_{n}^{-}\right]
$$

The identity,

$$
k_{\mathrm{trs}} \sum_{m}\left[\mathrm{M}_{m}{ }^{+}\right][\mathrm{S}]=k_{\mathrm{t}}\left[\mathrm{S}^{+}\right]\left[\mathrm{M}_{n}{ }^{-}\right]
$$

is implied by this equation and conforms to a stationary-state assumptions for $\left[\mathrm{S}^{+}\right]$.

With the assumption of a single rate constant in eq 2 for bimolecular termination reaction between charged species, and from the equation of charge conservation

Then

$$
\sum_{m}\left[\mathrm{M}_{m}^{+}\right]+\left[\mathrm{S}^{+}\right]=\left[\mathrm{M}_{n}{ }^{-}\right]
$$

$$
\left[\mathrm{M}_{n}{ }^{-}\right]=\left(R_{\mathrm{i}} / k_{\mathrm{t}}\right)^{1 / 2}
$$

whence

$$
\sum_{m}\left[\mathrm{M}_{m}{ }^{+}\right]=R_{\mathrm{i}} /\left[\left(R_{\mathrm{i}} k_{\mathrm{t}}\right)^{1 / 2}+k_{\mathrm{trs}}[\mathrm{S}]\right]
$$

and

$$
R_{\mathrm{p}}=R_{\mathrm{i}} k_{\mathrm{p}}[\mathrm{M}] /\left[\left(R_{\mathrm{i}} k_{\mathrm{t}}\right)^{1 / 2}+k_{\mathrm{trs}}[\mathrm{S}]\right]
$$

This scheme thus accounts for the negative first order dependence on solvent concentration which is in conformity with experimental data. This scheme is applicable for initiation by both types of ionic species.

\section{Structural Relationship and Rates of Polymerization}

It can be seen from the values given in Tables I and II that at all concentrations, the rates of polymerization of MCMA are greater than the rates at the respective concentrations of MPMA. The only difference in structure between MPMA and MCMA is the methyl group in the para-position of the benzene ring. This group probably increases the electron density at the site of the double bond facilitating the ionic polymerization. This conclusion is supported by the observation that the apparent activation energy for MCMA at 0.3 $\mathrm{Mrad} \mathrm{h}^{-1}$ is lower than that of MPMA at the same dose rate.

\section{Relative Rates and $\mathrm{G}\left(-\mathrm{C}_{7} \mathrm{H}_{8}\right)$}

The rates of bulk polymeriztion $R_{0}$ at $30^{\circ} \mathrm{C}$, at the dose rate of $0.3 \mathrm{Mrah}^{-1}$ and in the presence of nitrogen calculated for MPMA $=1.1 \times 10^{-4} \mathrm{moll}^{-1}$

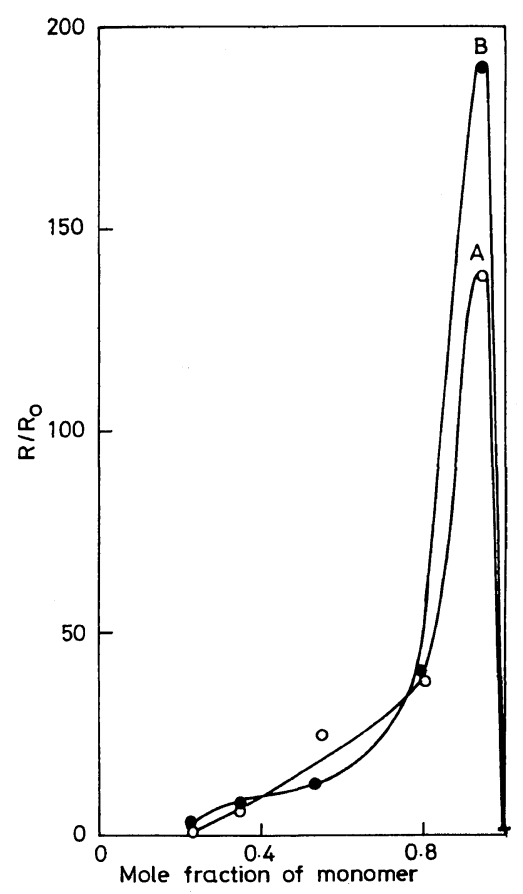

Figure 8. Plot of relative rates $\left(R / R_{0}\right)$ for MPMA (A) and for MCMA (B) at $0.3 \mathrm{Mrad} \mathrm{h}^{-1} v s$. mole fraction of monomer. 


\section{R. Devarajan, T. Balakrishnan, M. Santappa, and B. Viswanathan}

$\mathrm{s}^{-1}$ and for $\mathrm{MCMA}=1.32 \times 10^{-4} \mathrm{moll}^{-1} \mathrm{~s}^{-1}$ have been used in the evaluation of the relative rates $R / R_{0}$ for various monomer concentrations. These values which are of the order of $10^{2}$ are very high compared to free-radical polymerization. ${ }^{12}$ However, these values were plotted against the respective mole fractions (Figure 8 ) in an attempt to determine the $G\left(-\mathrm{C}_{7} \mathrm{H}_{8}\right)$. Unfortunately, to our knowledge, such plots are not available for comparison.

Acknowledgement. One of the authors (RD) is grateful to the University Grants Commision, New Delhi for the award of a teacher fellowship. The authors express their thanks to the staff, RSIC, IIT Madras for permission to use for $\gamma$-source.

\section{REFERENCES}

1. N. N. Rozovskaya, A. P. Sheinker, and A. D. Abkin, Vysokomol. Soedin., Ser. A, 7, 1388 (1965); Chem. Abstr., 63, 8271ce (1965).

2. N. N. Rozovskaya, A. P. Sheinker, and A. D. Abkin, Radiats. Khim. Polim. Mater. Simp. Moscow (1964), 92, discussion 197 (Pub.1966); Chem. Abstr., 66, $115987 \mathrm{~g}$ (1967).

3. A. Chapiro and R. Gouloubandi, C. R. Acad. Sci., Ser. C, 5, 277 (1973); Chem. Abstr., 79, 79304q (1973).

4. A. Chapiro and R. Gouloubandi, Eur. Polym. J., 10, 1159 (1974).

5. A. Chapiro, Eur. Polym. J., 9, 417 (1973).

6. J. Czajkowski, E. Turska, and J. Kroh, Bull. Acad. Pol. Sci., Ser. Sci. Chim., 14, 861 (1966); Chem. Abstr., 66, 116018d (1967).

7. K. Ueno, F. Williams, K. Hayashi, and S. Okamura, Trans. Faraday Soc., 63, 1478.(1967).

8. K. Ueno, K. Hayashi, and S. Okamura, Polymer, 7, 431 (1966).

9. H. Yamaoka, K. Nishiyama, K. Hayashi, and S. Okamura, Kobunshi Kagaku, 24, 649 (1967); Chem. Abstr., 68, 115172d (1968).

10. K. Murata, J. Polym. Sci., A-1, 5, 2942 (1967).
11. R. Devarajan and T. Balakrishnan, Polym. Bull., 1, 437 (1979).

12. A. Chapiro, "Radiation Chemistry of Polymeric Systems, Interscience, New York, N.Y., 1962, pp 145-192; 250-334.

13. L. A. Miller and V. T. Stannett, J. Polym. Sci., A-1, 7, 3159 (1969).

14. H. Yamaoka, K. Hayashi, and S. Okamura, Makromol. Chem., 76, 196 (1964).

15. H. Yokota, Y. Otsuka, T. Kagiya, and K. Fukui, $J$. Polym. Sci., A-1, 5, 2825 (1967).

16. M. Miura and M. Maruko, Kogyo Kagaku Zasshi, 67, 1077 (1964); Chem. Abstr., 61, 12093a (1964).

17. I. Sakurada, N. Ise, and S. Kawabata, Makromol. Chem., 97, 17 (1966).

18. S. Machi, S. Fujika, and T. Kagiya, Kogyo Kagaku Zasshi, 70, 388 (1967); Chem. Abstr., 67, 22301j (1967).

19. I. E. Kugacha, P. Colombo, and M. Steinberg, $J$. Polym. Sci., C., No. 16, 579 (1967).

20. H. Yamaoka, R. Uchida, K. Hayashi, and S. Okamura, Kobunshi Kagaku, 24, 79 (1967); Chem. Abstr., 67, 22303k (1967).

21. A. Hinschnerger and J. Marchal, C.R., 258, 2327 (1964); Chem. Abstr., 60, 14709f (1964).

22. D. J. Metz, Adv. Chem. Ser., 66, 170 (1967); Chem. Abstr., 68, 40148q (1968).

23. J. F. Westlake and R. Y. Huang, J. Polym. Sci., A-1, 10, 1429 (1972).

24. R. C. Potter and D. J. Metz, J. Polym. Sci., A-1, 9, 441 (1971).

25. C. C. Allen, W. Oraby, T. M. A. Hossain, E. P. Stahel, D. R. Squire, and V. T. Stannett, J. Appl. Polym. Sci., 18, 709 (1974).

26. D. R. Squire, J. A. Cleaveland, T. M. A. Hossain, W. Oraby, E. P. Stahel, and V. T. Stannett, J. Appl. Polym. Sci., 16, 645 (1972).

27. J. Kohler and V. T. Stannett, Polym. Prepr., Am. Chem. Soc., Div. Polym. Chem., 12, 98 (1971); Chem. Abstr., 78, 16545c (1973).

28. T. A. Du Plessis, A. M. Goinean and V. T. Stannett, J. Polym. Sci., Polym. Chem. Ed., 12, 2457 (1974).

29. T. Hiromoto, M. Nishii, K. Hayashi, and S. Okamura, J. Polym. Sci., A-1, 9, 3647 (1971).

30. Ff. Williams, K. Hayashi, K. Ueno, K. Hayashi, and S. Okamura, Trans. Faraday Soc., 63, 1501 (1967). 